\title{
Relative rhythms, urban oases, and spatial resilience / Exploring syntaxes of seclusion, solitude, and tranquility
}

\author{
Daniel Koch* (D)
}

\begin{abstract}
This article engages with the role of what one might tentatively call "secondary" urban spaces, in that while they are public, they are not the most vibrant, populated, or active places. These are not the spaces envisioned in many project illustrations. They are not full of people and activity. They are however a crucial part of a wider texture of urban situations, and important to extending our understanding of seclusion, solitude, and tranquility beyond distant parks and recreation areas. My aim here is to understand the emergence of these spaces in-between; those that are close to the vibrant streets and are embedded in city centers, yet which offer a respite from the most bustling urbanity. These spaces, I will argue, more easily allow for the kinds of interactions that can lead to bridging and bonding with the unknown, in addition to the important everyday encounters that occur on central streets and squares. Using qualitative methods which build on Lefebvre's rhythmanalysis, the discussion will draw on observations of the syntactic properties that condition, enable, and characterize such spaces, and address a series of concepts, including capacity, insulation, sequencing, and interface. A better understanding of such places, it is argued, not only allows a richer set of tools for working with urban design and planning but offers possibilities for more resilient planning in terms of generating social relations, the emergence of communities, and for cities to manage and withstand extraordinary conditions.
\end{abstract}

Keywords: rhythm analysis, space syntax, resilience, urbanity, urban design

\section{Introduction}

A growing body of research has in recent years highlighted the importance of spaces for rest and pause in contemporary cities. In the field of urban design, "rest" is regularly raised in relation to green spaces, health challenges, and issues of stress and mental well-being (Anderson, Ruggeri, Steemers, \& Huppert, 2016; Barthel \& Kyttä, 2020; Engström \& Gren, 2017; Park \& Evans, 2016; Roe \& McCay, 2021). Red threads that run through this existing scholarly work include an interest in improving accessibility to parks and recreational green spaces for individuals, recurring discussions of "urban versus rural" environments, and a common tendency to romanticize the periphery; amongst planners and architects, and in line with the UN Sustainability Goals, a greater 
number of vibrant, open (green), public spaces for social exchange is seen as central solutions in addressing the problem of rest in contemporary cities (United Nations, 2015). In the contemporary planning paradigm, open spaces within intense urban areas are thus celebrated for their "vibrancy," while larger green areas are valorized in terms of their scenic and functional qualities in relation to the intentional recreational activities that they are to support. While I acknowledge the importance

Page 57 of such spaces within urban environments, this paradigm risks reinforcing dichotomies (Samuelsson, 2021), treating public space as a homogeneous mass (Koch, 2021), and-ultimatelymisunderstanding the concept of "rest."

In this article, I investigate the spaces of everyday life in cities that, while not the most bustling squares, streets, or parks, are often present and arguably necessary for urban life and resilience. In some ways, my argument continues Gustav Engström and Åsa Gren's advocacy of the need for slower rhythms and seclusion when incorporating qualitative green space in dense environments (Engström \& Gren, 2017). The paper adopts a multifaceted view of the concept of resilience (Walker, Holling, Carpenter, \& Kinzig, 2004) and builds on existing knowledge about the relations that link configurational structures of space with emergent collective behavioral patterns (Hillier \& Hanson, 1984). The fieldwork draws on Lefebvre's rhythmanalysis (Lefebvre, 1996b, 2004) and makes use of my own experiences as a participant in urban life, addressing both events and everyday situations and the ways in which our understanding of spaces unfolds over time. Such broad knowledge is complemented by structured visits in two forms: specific, documented research visits (Figure 1) and visits conducted in the course of teaching.

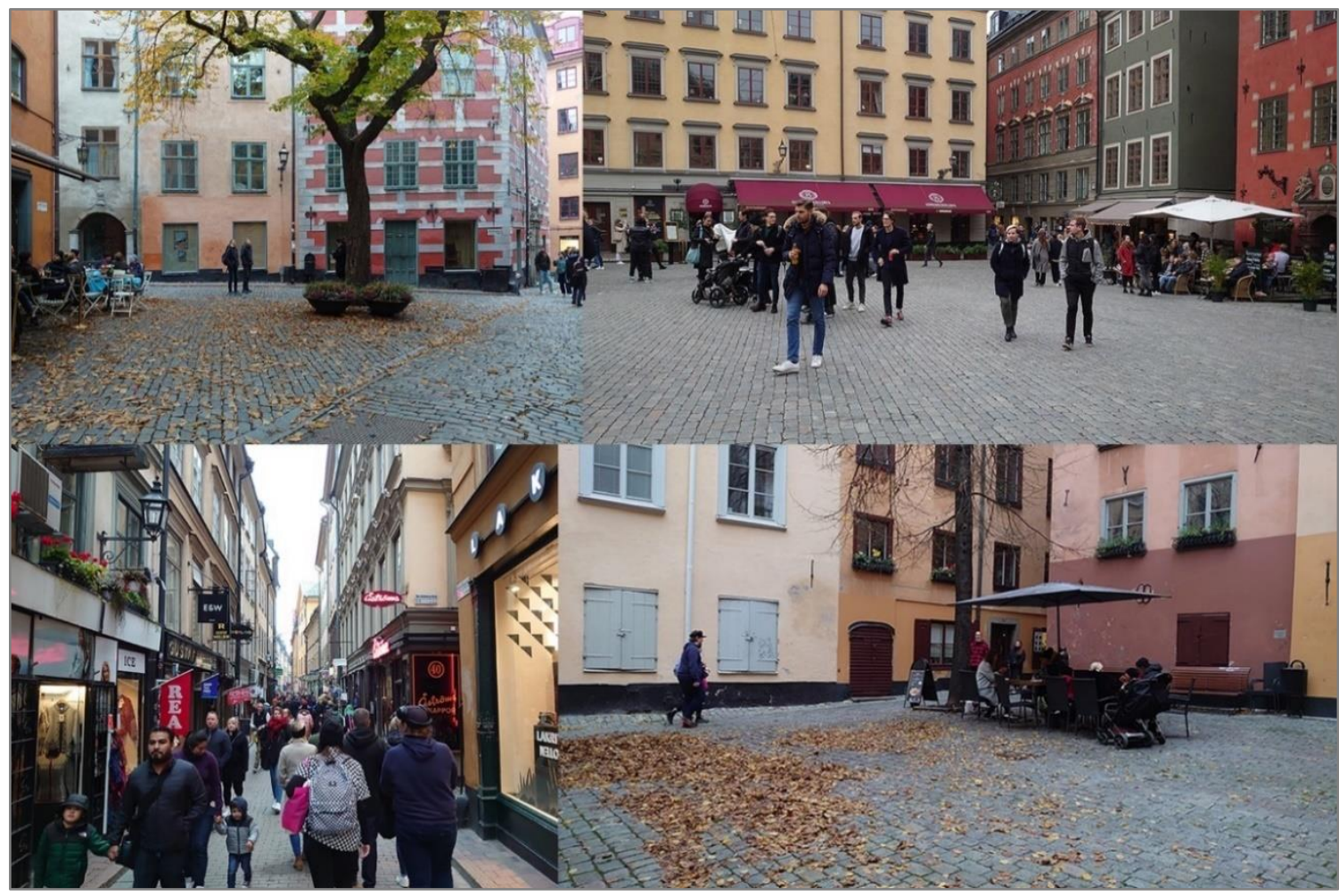

Figure 1 A targeted visit/walk on October 30, 2021. The photographs are taken within 10 minutes (14.16-14.25), and demonstrate the radically shifting degrees of "vibrancy" in public spaces in Gamla Stan, Stockholm. The phogographed locations are Brända Tomten, Stortorget, Västerlånggatan and Gåstorget. The photograph of Västerlånggatan is taken from high vantage point in order to show how far the density of bodies extends along the street. The locations are shown on the map in Figure 2 Photographs by the author.

I will engage with a series of situations that I have chosen, aiming to qualitatively bring out the specific characteristics and atmospheres of their locations, to learn from particularities, and to avoid quasi-statistical tendencies. I acknowledge that the selection is limited to environments with a middle-class demographic - the areas they are embedded in have become increasingly gentrified in recent decades-and as such that one needs to be careful in generalizing from such particulars. 


\section{Rhythmanalysis and Configurative Analysis}

Movements through the city are, by virtue of social and spatial modes of organization, unequally necessary in daily life: similarly, individual rhythms are polyrhythmic and may or may not follow emergent normative or collective rhythms (Amin, 2008; Koch \& Sand, 2009). Rhythms therefore form externally recognizable patterns, through which we can better understand our cities (Koch, 2017; Netto, 2008). By identifying relations between built form and urban rhythms, in this paper I argue that configurational research offers possibilities to understand how the re-organization of space might affect rhythms, redistribute flows, and recharacterize individual spaces and spatial patterns.

There are clear challenges in combining the works of Henri Lefebvre with those of Hillier, Hanson, and others; not least because Lefebvre is often critical of the kind of statistical analysis that is prevalent in syntactic research. I do not claim to resolve this tension and acknowledge that bringing the theories together affects how both are to be understood. At the same time, Lefebvre is not wholly negative to structural analysis and quantitative research (Lefebvre, 1991). On the contrary, rhythmanalysis aims to combine the two:

"Rhythm reunites quantitative aspects and elements, which mark time and distinguish moments in it - and qualitative aspects and elements, which link them together, found the unities and result from them" (Lefebvre, 2004, pp. 8-9).

Rhtyhmanalysis becomes a way of structuring the combination of disparate methods, but also of qualifying each, as well as their interrelation. I combine rhythmanalytic understanding with qualitative configurational discussions, bringing in knowledge from quantitative syntactic studies: I understand correlations to form a quantitative basis for a qualitative understanding of collective urban rhythms over time. From a rhythmanalytic perspective, syntax research can help us to better understand relations between linear and cyclical rhythms and the organization of urban architectural space. If rhythms in part are a result of "social organization manifesting itself" (Lefebvre, 1996a, p. 222), one can also find theoretical links to spatial configuration: in particular, I note that large parts of The Social Logic of Space address "the ways in which society materializes itself" (Hillier \& Hanson, 1984) and John Peponis similarly describes "the pedagogical function of the city" (Peponis, 2017)-both can arguably be used to frame a relation between spatial configuration and spatial practice (Lefebvre, 1991).

There are challenges with Lefebvre's rhythmanalysis. Aside from the introductory comments on the Rue Rambuteau, the discussion remains largely abstract. For instance, in "Attempt at the Rhythmanalysis of Meditteranean Cities" (Lefebvre \& Régulier, 2004), specificity and difference get lost amongst generalizations that, as Emily Reid-Musson points out, tend towards essentialism (Reid-Musson, 2018), entertains a series of contradictions, and leans into dualisms, including a "nostalgic and, at bottom, moralistic idea about modern time regarded as mechanic and unhealthy, as opposed to the ancient time seen as organic and curative" (Brighenti \& Kärrholm, 2018).

While the participation of the researcher or analyst in rhythms - or what Brighenti and Kärrholm call the "immediately affective dimension" (Brighenti \& Kärrholm, 2020, p. 159)-has become a dominant focus in continued work, rhythmanalysis builds on both observations from the "outside" and experiences from the "inside." As Lefebvre and Régulier put it, "Externality is necessary; and yet in order to grasp a rhythm one must have been grasped by it, have given or abandoned oneself 'inwardly' to the time that is rhythmed" (Lefebvre \& Régulier, 2004, p. 88). As Claire Revol notes, this combination also makes rhythmanalysis qualitatively different from, for instance, phenomenological studies, since "the main concern of the rhythmanalyst is not to say that there are rhythms, that rhythms exist, but to analyse them and to find what they reveal about what they are supposed to link: time, space and energy" (Revol, 2019, p. 5). In light of this insight, I have employed a concrete and localized understanding in my work wherein rhythm acts as a method and 
an analytic tool, precisely because the "localisation and materialisation of time through rhythm that makes the concept of rhythmanalysis interesting for analytical use" (Osman \& Mulíček, 2017, p. 47).

In the fieldwork, I have used of a combination of targeted research efforts and knowledge gathered over time, combining the possibilities embedded in lived spatial practice with a critical use of specific actions to test the validity of routinized experience. This fieldwork further builds on Monica Sand's suggestions around walking (and getting lost) in the city as an analytic tool (Sand, 2011). The fieldwork has covered a wider variety of places for a wider purpose, but the situations discussed here were chosen because they are in line with regularly occurring rhythms on the sites in question and because in their specificity they highlight particular aspects of rhythms. In this sense, they act similarly to the "particulars" used by Paulina Pietro de la Fuente in her study of squares and rhythms of eating in Malmö (de la Fuente, 2015). In line with Lefebvre's intent, observations are central to the study; as Revol writes, "...observation has a special place in rhythmanalysis because it is integrated in the process of analysis as well as the definition of what is being analysed" (Revol, 2019, pp. 5-6).

\subsection{Configurational understanding of Stockholm, and the use of open space for seclusion in the} pandemic

I make use of existing research for the "external" observation; I support my argument through recourse of repeated studies of Stockholm that have consistently demonstrated a strong correlation between movement flows at the observation locations and the syntactic properties of those locations (Choi \& Koch, 2015; Legeby, 2013; Marcus, 2000). The streets that I describe as "lively" in this study all belong to the "integration core" of Stockholm and of the various island neighborhoods in which they are situated (for those unfamiliar with the city, Stockholm is built in an archipelago setting, between the Lake Mälaren and the Baltic Sea). The configurational roles of these locations are pervasive; they are central at both local and global scales, and in terms of both closeness and betweenness centrality ("integration" and "choice"). They are furthermore important connectors between and across islands, extending via bridges to reach further into the urban fabric, and their vibrant characters contribute to the way in which their contexts are perceived as lively urban areas.

Here I note another important aspect that ties rhythmanalysis and syntactic analysis together: both modes of analysis primarily deal with relativity. Correlations between spatial configurations and behavioral data are almost exclusively relational. That is, more central spaces or less central spaces correlate to more intense uses or less intense uses. This article considers configurational analysis of space to uncover hierarchies of visibility and accessibility, and thereby identify the characteristics that make places more central or less central, easier to find or less easy to find, and more intensely used or less intensely used. As Lefebvre and Régulier put it:

"Let us insist of the relativity of rhythms. They are not measured as the speed of a moving object on its trajectory is measured, beginning from a well-defined starting point (point zero) with a unit defined once and for all. A rhythm is only slow or fast in relation to other rhythms with which it finds itself associated in a more or less vast unity" (Lefebvre \& Régulier, 2004, p. 89).

Similarly, rather than understanding seclusion, solitude, or tranquility as absolutes, I understand them as relative concepts: in a bustling central area, seclusion can be achieved in a fairly well-visited café, whereas in less vibrant environments, a sense of seclusion or solitude may require spaces where one can be more explicitly "alone." This is not to advocate total relativism; boundaries, contexts, and limitations (of material, social, cultural, and biological kinds) all exert influence in defining these relations.

Finally, while this study was initiated prior to the Covid-19 pandemic and engages with wider urban questions, the ways that it has been stress-tested within the urban fabric in the past year 
offer additional relevant perspectives. As Sweden took a different path from other countries during the pandemic, focusing restrictions on physical distancing and citizen responsibility-including recommendations to work mostly from home (Ludvigsson, 2020)-many people made more intensive use of their local environment's public spaces (Bohman, Ryan, Stjernborg, \& Nilsson, 2021). The pressure on parks, squares, and nature areas increased noticeably, and they became an important part of enabling degrees of socialization and recreation (Legeby \& Koch, 2020) and personal well-being (Samuelsson, Barthel, Giusti, \& Hartig, 2021). This included both "on-the-side" spaces and larger recreational areas in more peripheral locations, whereas some of the usually most intensely used locations were rather avoided. While these patterns have been confirmed by many different sources, from phone tracking to Twitter use, responses in a web-based PPGIS questionnaire also demonstrate the importance of "finding seclusion" in public space, preferably "close by" (Legeby \& Koch, 2020).

\section{Emplaced rhythms}

\subsection{Gamla Stan: Tyska Brunnsplan and Brända Tomten}

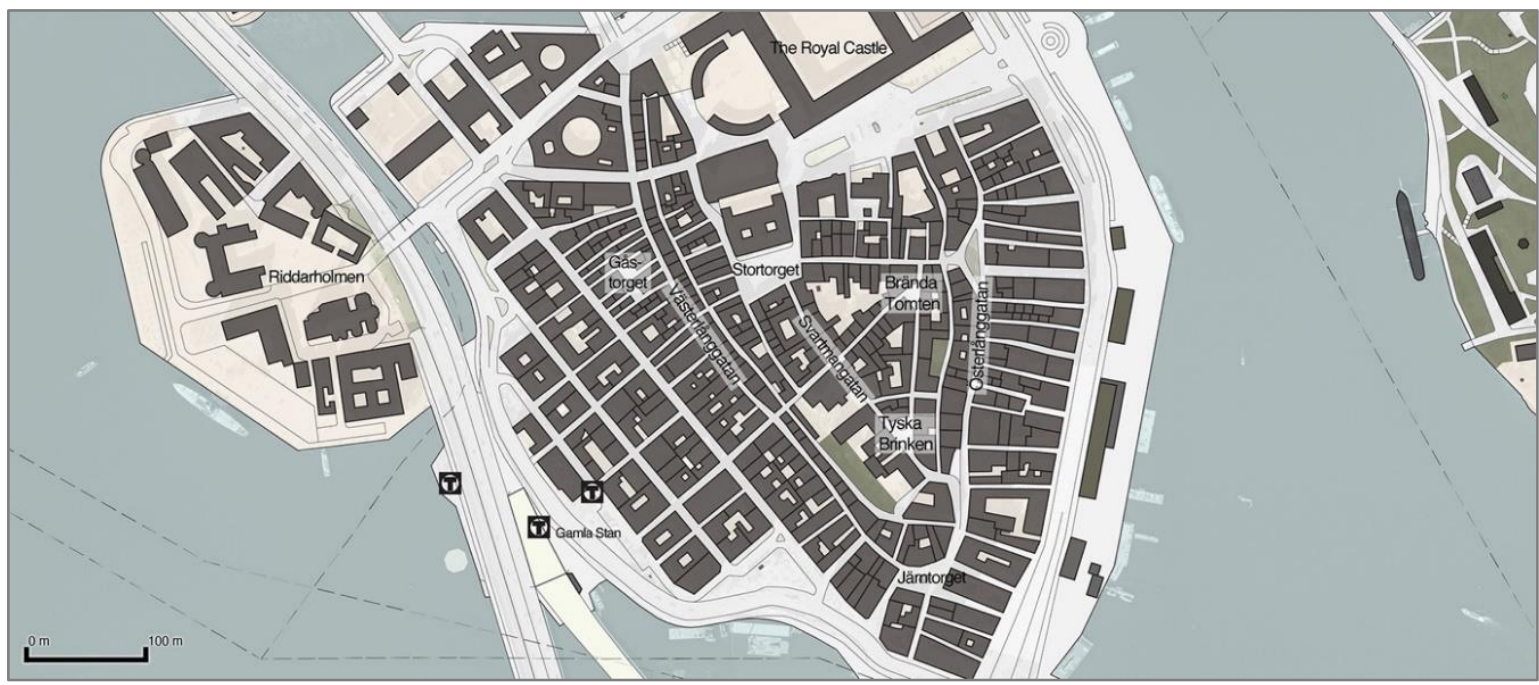

Figure 2 Tyska Brunnsplan; distance to Järntorget is $137.5 \mathrm{~m} / 115.5 \mathrm{~m} / 5$ turns; distance to Västerlånggatan is $147.75 \mathrm{~m} / 76 \mathrm{~m} / 2$ turns / (107.8 m to intersection); distance to Stortorget is $162.5 \mathrm{~m} / 160.4 \mathrm{~m} / 2$ turns; distance to the nearest subway station is $413 \mathrm{~m} / 295.5$ m / 3-4 turns; distance to the Royal Castle is $284 \mathrm{~m} / 242.5 \mathrm{~m} / 3-4$ turns (4 to entry, 3 to square). Brända Tomten: distance to Stortorget is $142 \mathrm{~m} / 115 \mathrm{~m} / 2$ turns; distance to Järntorget is $305 \mathrm{~m} / 230 \mathrm{~m} / 5$ turns; distance to Västerlånggatan is $157 \mathrm{~m} / 154 \mathrm{~m} / 2$ turns; distance to the nearest subway is $368 \mathrm{~m} / 315 \mathrm{~m} / 4-5$ turns; distance to the Royal Castle is $173.5 \mathrm{~m} / 131 \mathrm{~m} / 3-4$ turns.

Tyska Brunnsplan, August 31, 2021, 14.05

As we resume our walk from Stortorget - which, after more than a year of Covid-19 restrictions, is full of people in the outdoor dining areas, moving across or lingering on the square, sitting on the stairs of the Nobel Museum, or participating in guided tours in the Old Town-we rather quickly find ourselves to be the only ones walking along Svartmangatan, a small street that is on the shortest path between the square we just left and the square we are aiming towards, Järntorget. We have walked here from the comparative quietness of Riddarholmen, passing the major tourist and commercial street Väseterlånggatan and making our way up to the Royal Castle, with its gathering of tourists. Now once again we are outside of the area of bustle that we entered into not so long ago. By Tyska Brunnsplan, we are mostly alone, save for two older people, who study us briefly as if trying to figure out who we are; I begin speaking to the students and they quickly lose interest. Another group of tourists, they seem to assume. We remain there for a few minutes, discussing how quickly we ended up outside of the lively atmosphere that most of the students associate with Gamla Stan. As one of the few squares with a large tree in this part of the city, we notice that we haven't seen any greenery for a while and that we have consistently been walking on various kinds of cobble or pavement. The streets that we have walked along have been narrow, 
especially Västerlånggatan, which we only followed for a short distance before finding an alternative route, as the size of our group conflicted with other bodies moving along the street and attempts to keep the group together only made such conflicts worse. The sun is shining at an angle that highlights the tree and the fountain beneath it, and the absence of cars in the wheelchairaccessible parking bay suggests that this would be an ideal place to sit and read, or have a low-key conversation, or just rest for a bit. While that would be possible on Stortorget as well, the atmosphere here is drastically different: resting here would be a very different activity than resting there (Verschaffel, 2010). The square, however, doesn't offer any immediate opportunity to do so.

Brända Tomten, October 30, 2021, 14.15

Arriving from Järntorget this time, I pass through Tyska Brunnsplan, which is again empty of people. I am briefly frustrated by the fact that there are three cars parked in what last time was an excellent place to pause and continue down to another square we have often visited on study trips (although not in the walk described above). Brända Tomten is slightly larger than Järntorget, and along the western side of the mostly triangular square the café Under Kastanjen ("Under the Chestnut Tree") has an area for outdoor dining that is open-slightly less than half the seats are filled. The atmosphere is calm and quiet; aside from the al fresco diners, the square is largely empty when I arrive, and few people pass by. It is a bit colder, and the sun is a bit lower, than on my previous visit, but it is still a pleasant day and I remain there for a short while reading. People come and go. Most groups are small, and people appear to already know each other; they tend to be either heading for the café, towards Stortorget or to the nearby bus stop. Of those going to the café, it is easy to discern three categories of customer: tourists, who are guided to the place by smartphones or guidebooks; people who clearly know of the café and come straight to it; and "locals," who can be distinguished through snippets of overheard conversations. "Drop-in" customers - those that "discover" the café as they meander the streets-are rare. Those heading towards Stortorget come in small bursts, most likely from the bus stop. A few others also spend time here, and I notice how easy it is to follow the actions of almost any individual on the squarein fact, it is almost difficult not to. Those of us present here, not counting the café-goers, each exchange eye contact at least once, and in this single act of minimal interaction, we become coaware. A change has been made, recently: the square used to be separated into public benches and outdoor dining, but the dining area has been rearranged to run along the whole length of the façade, which has meant removal of all public benches (Figure 3). As I am about to leave, a larger group begins to gather, so I stay to watch as the group slowly increases in numbers; some kind of guided tour is initiated, and they begin to split into different smaller groups. They do not interfere, the square is still calm and spacious, and it does not seem to inconvenience anyone that they gather here, like it would if they gathered on the more densely visited squares or in a more clearly territorialized place. They seem to be unusual enough to arouse curiosity, judging by overheard conversations, but not unusual enough to become an event. Once they disperse, I begin to sense that I too am growing into a curiosity, spending more time than the square's rhythm suggests, doing nothing but hanging around and watching. I leave and move across Stortorget to Västerlånggatan, crossing two thresholds of noticeably increased vibrancy-at the latter to the extent that even alone, I need to navigate the bustle of bodies so as to not be in the way, to find my way forward, and to not (too often) bump into anyone. 


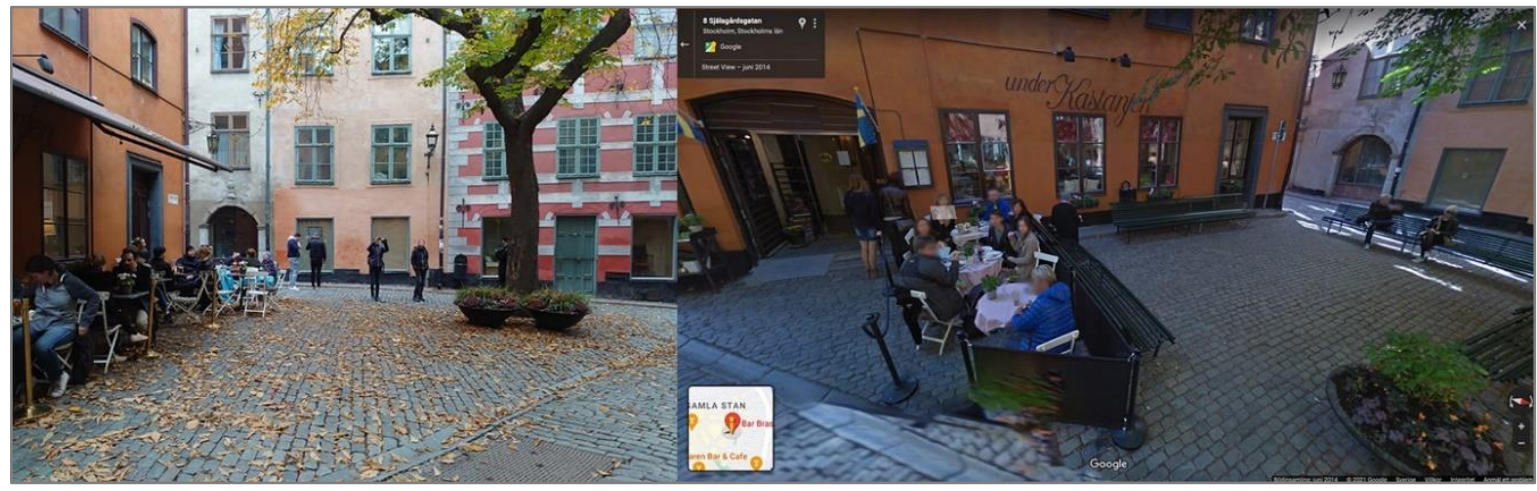

Figure 3 The outdoor dining area in a contemporary image (October 30, 2021) and the arrangement in 2014 (Google Streetview) showing the replacement of public benches by the outdoor serving of Under Kastanjen. Photograph by the Author and from Google (৫) Google 2014).

These episodes play out at two locations which I have visited the first week of the semester after summer for several years, as they are part of a study visit that we take our students on in their first week of the Masters' program in Sustainable Urban Planning and Design at KTH Royal Institute of Technology. The walk is arranged to include aspects of what this article is concerned with, highlighting the closeness in central Stockholm of radically different rhythms. Starting from the Gamla Stan subway station, the walk goes west to the waterfront of Lake Mälaren, continuing around Riddarholmen up to and through a section of Västerlånggatan, to the Roayal Palace, further to Stortorget and then past Tyska Brunnsplan and/or Brända Tomten to Österlånggatan, and on to where this street meets Västerlånggatan at Järntorget, from where we continue to Södermalm. Usually done in the morning, this year saw it was performed three times in the afternoon instead, as we needed a Covid-safe solution and decided to do stage the walk multiple times, in smaller groups. In preparing and performing these study walks, as well as other more extended observations, it has become clear that these kinds of squares exist in many places on the island; there are remarkably many, although the extent to which a given square is included in the tourist economy varies.

\subsection{Skinnarviksparken, June 7, 2021, 17.45}

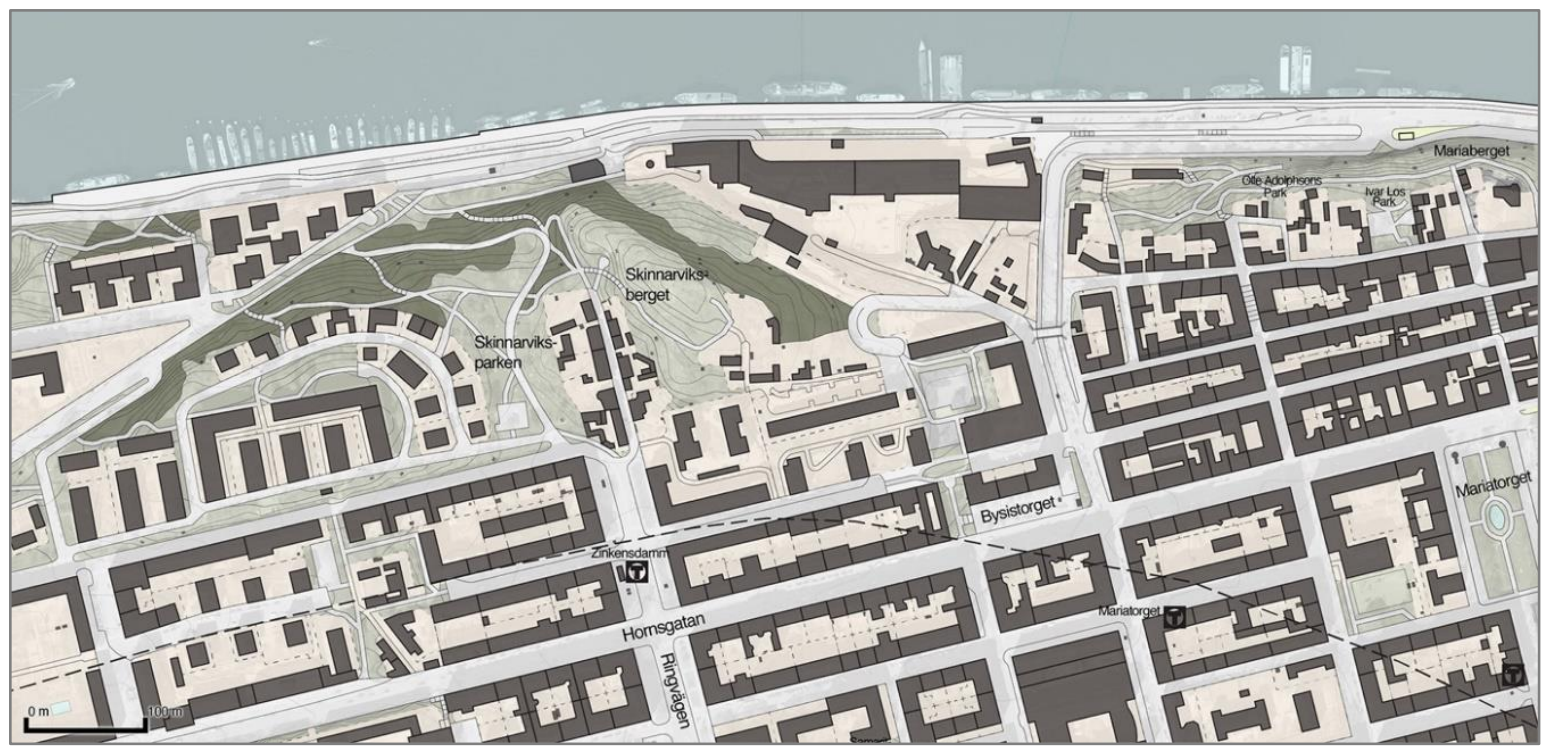

Figure 4 Skinnarviksparken and surrounding context. The distance to Hornsgatan is $222 \mathrm{~m} / 205 \mathrm{~m}$ ( $211 \mathrm{~m}$ to intersection) / 2 turns (+1 for Hornsgatan direction); distance to nearest subway station is $190 \mathrm{~m} / 176 \mathrm{~m} / 3$ turns ( +1 to enter, -1 to reach the "side of the entrance building"); distance to Bysistorget is $513 \mathrm{~m} / 417 \mathrm{~m} / 4$ turns (including entering Bysistorget, 5 turns shortest metric path); distance to Mariatorget is $1010 \mathrm{~m} / 816.5 \mathrm{~m} / 4$ turns (including entering Mariatorget). 
It is early evening in the summer. While there are Covid-19 restrictions in place, outdoor gatherings are allowed, following a reduction of restrictions that has been in place since June 1 , 2021. One of our doctoral students has just defended her thesis and I join a small outdoor celebration. We are around twenty people, clustering in smaller groups around picnic blankets, close to one edge of the park. There is easily enough space to physically distance from other groups. In the warm summer evening, the environment offers a pleasant blend between a bit of quiet celebration and the occasional intense conversation or discussion, and louder congratulations from new arrivals. While at other times of the year, our chosen spot may be at its best in the morning or at midday, we have a fair amount of sunshine until quite late. Some other groups, mostly somewhat smaller than ours, have gathered on the other side of the pedestrian path, and especially on the other side of a small sets of bushes offering a light screen of vegetation between us and them. As the evening continues, there is a steady, but small, stream of pedestrians walking through the park. Some stop to sit on available benches, and the occasional pair or lone wanderer take a seat under a large tree or on the sunlit rock to have coffee, converse, or read. The café at the entrance of the park remains open for some of the time, but for the most part, their activity and those of other groups never collide, and at least today none of the groups seem to end up in competitive behavior in terms of music or activity, even as further groups turn up during the evening.

Skinnarviksparken is a mid-sized park by one of the main arteries of Södermalm in the center of Stockholm. It is also next to a subway station. The part of the park addressed here is the grasscovered section closest to the station. The park extends over a rather steep, mostly bush-covered slope, which is crisscrossed with steep pedestrian paths, and takes in the rocky hilltop of Skinnarviksberget, which is more remote. The part that we gather on is also most clearly integrated into pathway networks between the adjacent (predominantly housing) area, the subway, and busy street Hornsgatan. While the grass area tends to remain mostly calm, it is used throughout, and the rocky surfaces of the hilltop fluctuate more between emptiness and larger and noisier weekend evening parties, as its comparative remoteness allows for more noise without disturbing surroundings. For a number of years, I have been able to incorporate the park in my routines $-m y$ two weekly jogging rounds pass through it-allowing me to capture the rhythm and character of the park repeatedly over an extended period, in addition to more targeted observational visits.

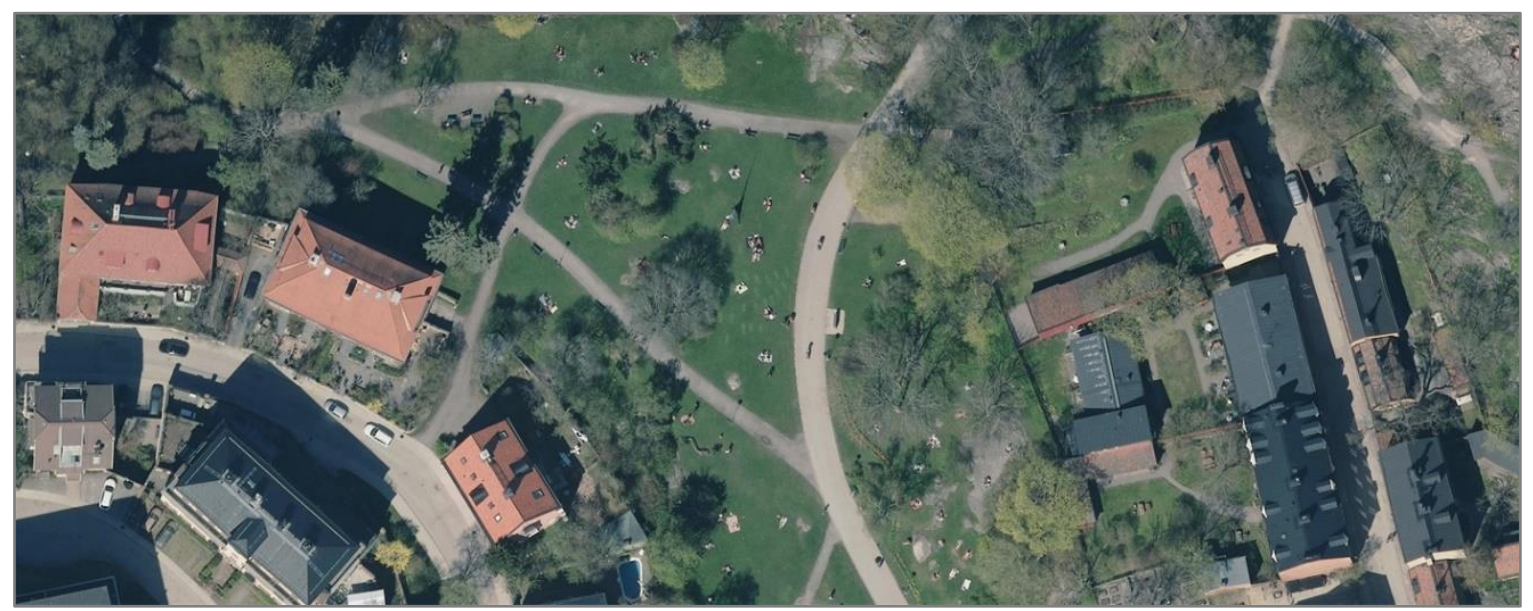

Figure 5 Inhabitation of Skinnarviksparken on a sunny summer day, showing the emergent results of a spatial negotiation of the surface as well as the degree of occupation. Aerial photo by Stockholms Stad (C Stockholms Stad 2019).

While Skinnaviksparken is a well-visited park, it almost always has space for more people-be it in the period of most intense sunbathing or on late evenings on the weekend. In contrast, the nearby square Bysistorget and the "green" square of Mariatorget often feel significantly more "full": they see more intense use, and they are also more directly linked to the central street network and Hornsgatan. Part of the park's capacity comes from its subdivision by natural and artificial elements: walkways and bushes make for strong and clear boundaries, whereas topography allows for further negotiation of territory if needed-two grass slopes with a rocky 
height in between can become one, two, or three territories quite easily, and throughout visits it is clear how the interplay between activity, the density of visits, and the environment interact in these territorial negotiations (Figure 5). This character and subsequent occupational patterns rhyme well with both Lars Marcus' discussion of capacity (Marcus, 2000) and with the findings in the Vienna park gender mainstreaming project (Irschik \& Kail, 2013), showing that parks which are divided into sub-spaces see more diverse use both in terms of kind of activity and occupants. While this capacity seems to act in line with the principles laid out by Marcus-more spaces offer more opportunities for diversity-it does so with less clearly drawn boundaries, since literal subdivisions offer only a weak support in the territorial negotiations between actors and activities.

\subsection{St. Axel Landquists Park, September 18, 2021, 13.40}

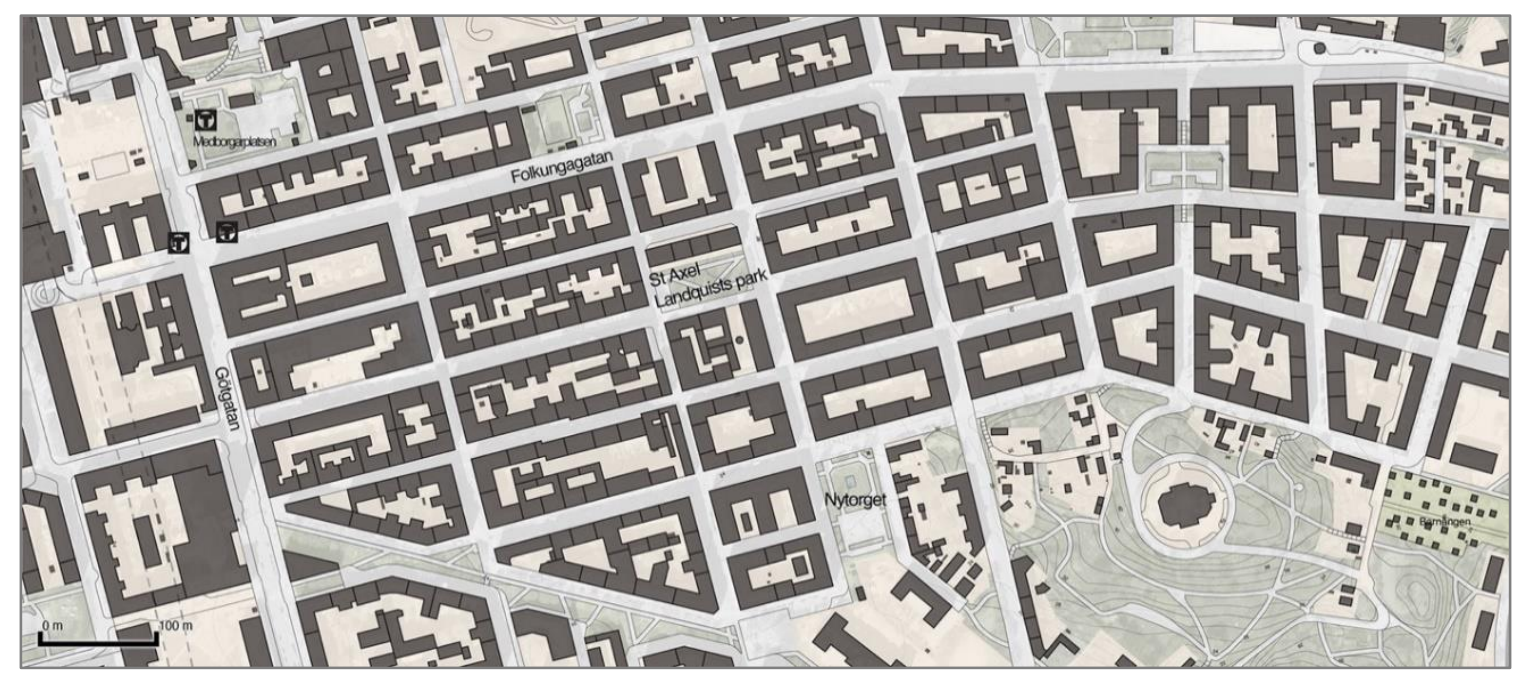

Figure 6 St. Axel Landquist's Park and its surrounding context. The distance to Folkungagatan is $155.8 \mathrm{~m} / 122 \mathrm{~m}$ (130 m to intersection) / 2 turns (including entering the park); distance to Götgatan is $413.5 \mathrm{~m} / 406 \mathrm{~m}$ (408 to intersection) / 2-3 turns (including entering the park); distance to Nytorget $251.2 \mathrm{~m} / 212 \mathrm{~m} / 2$ turns; distance to the subway is $503 \mathrm{~m} / 414.04 \mathrm{~m} / 3$ turns (including entering the subway); distance to Medborgarplatsen is $671 \mathrm{~m} / 505 \mathrm{~m} / 4$ turns.

This visit to St. Axel Landquist's Park is the first in a while, and I come here on a Saturday, together with a friend after a fairly long walk. It is mid-afternoon. We have decided to have an ice cream, as there is a small ice-cream stand that has opened here. It wasn't here a few years ago, when I had reason to pass by more often, and while we both like ice cream on a warm and sunny day, it irritates me that the stand is placed in the middle of the park, claiming central territory and privileging its own visibility instead of occupying a more peripheral space-even if the vast majority of the park remains open for public use. The stand, according to my friend who, living closeby, visits the park more often than I, does really well and the line for ice cream is sometimes long. Today, the queue is relatively short; while it is a pleasant day, the most intense sunshine of the Swedish summer is now over. Having bought our ice creams, we sit down for a bit and I inquire if it is usually difficult to find a place to sit. The answer is no, not really. Only sometimes. Still, the number of chairs is pretty small: just a few tables, with a few chairs each. Of course, on nice days, many choose to sit on the grass or on the public benches along the park's edges. The latter are also not full on this day, although we can't see all of them because the park is divided into sub-spaces by vegetation. The park meets the streets around it quite differently (Figure 7): in the north, it meets the building block directly, but a line of bushes clearly mark out the territory of the park. In other directions, the park is slightly higher than its surroundings, requiring one to take a few steps up or follow small ramps to enter. While directly connected to three streets, it is thereby also clearly demarcated as its "own" space. We sit for quite some time, discussing a variety of things, and I keep both conscious and sub-conscious track of the rhythm of the space, not the least whether it feels like we are blocking anyone else's use of the seats. During our time here, the seats never fill up, and there is always at least one table that is completely free. 
Page 65

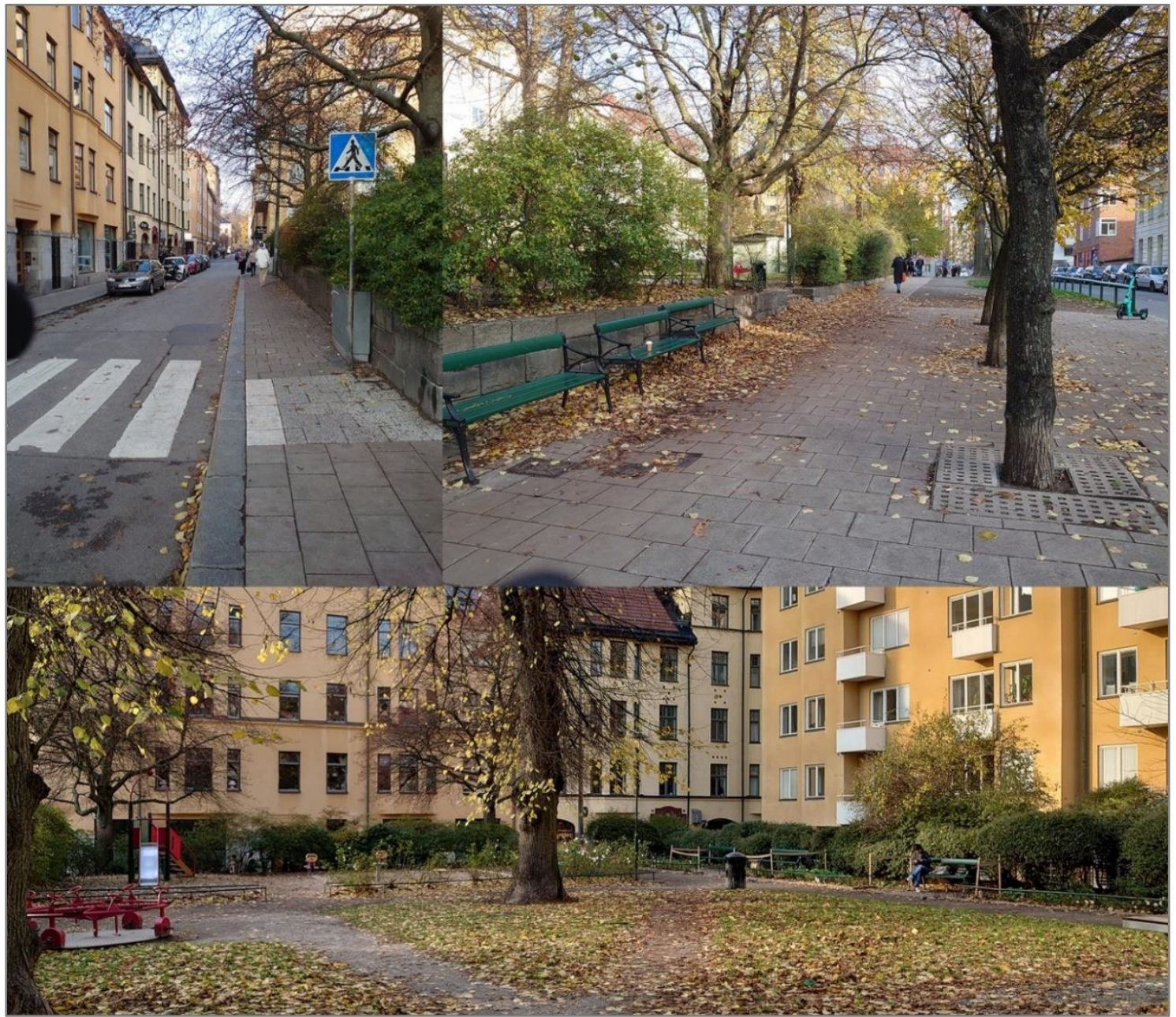

Figure 7 St. Axel Landquist's Park. A view of one side of the park and height differences at the entry. October 30, 2021. Photographs by the author.

St. Axel Landquist's Park lies just south of Folkungagatan and not far from Götgatan, two of the busiest streets on the southernmost island of inner-city Stockholm. It is in the area that has become known as "SoFo", paraphrasing the SoHo area in London in an attempt to reflect its intensity of use and the presence of "local" commercial actors-or at least different sets of brands than those found on the high street. As the SoFo nomer emerged, the brands also became increasingly high-end, confirming a growing gentrification. A group of friends and I regularly used to have breakfast at a (now defunct) café near the park on Saturdays, and as such I used to pass through this place fairly often; I lived further away, and it was on a convenient path from the subway to the café. It has always stuck with me as something of a quasi-hidden oasis, partially due to its intentionally separated character. Its character as an oasis is further supported by fellow researchers' observational studies, which note how the small park remains less intensely used than the streets around it-and significantly less so than the square Nytorget, which is not far away (Choi, 2014; Choi \& Koch, 2015; Legeby, 2013). As a walking path, its use seems to be primarily for what Choi calls "recreational" and "social" walking, characterized by slower pace, greater interaction with the walker's surroundings, and focus on relaxation. While I have visited the park less in recent years, its character seems to remain intact, even with the new the ice-cream stall. The stall, however, while ticking many of the identity boxes of Södermalm, wanders perilously close to what Sharon Zukin calls "pacification by cappuccino" (Zukin, 1995), and while being a local, conscious actor participates in a commercialization of public space however much it is appreciated by locals (Kärrholm, 2012). 


\section{Foreground Networks, Background Networks, and Characters of Social Interplay}

The tendency for seldom-frequented streets and squares to exist within the dense centrality cores of networks is explained in syntax research by the observation that choice and integration both tend to correlate with pedestrian flow, the latter exponentially (Marcus, 2000, p. 113; Stavroulaki, Bolin, Berghauser Pont, Marcus, \& Håkansson, 2019). My observations thus largely support previously documented statistical patterns but make tangible just how quickly intensity drops off: the places discussed here are between one and two blocks from some of Stockholm's most intensively visited locations. These patterns of centrality and movement flows have contributed to the theory of foreground and background networks (Hillier, 1999, 2009), which holds that networks can be conceptualized as "productive" or "reproductive" of social relations, that "difference" "meets" in the streets that bind the city together, and that local communities are built on the basis of that which is separated from them.

The sites discussed here ask for care and nuance in subjecting them to such a conceptualization. While not sites where differences meet as a result of the sheer density of flows through the city, they are not simply "local" either. Rather, they offer atmospheres for other kinds of interaction, or for breaks from the intensity of the high streets. Their qualities come specifically from being calm, quiet, slow, or otherwise less vibrant and intense than the central streets, while being close to those streets. As spaces that more easily accommodate more extended interaction, their closeness to larger urban arteries offers potentials of integration by both enabling and demanding interactions that are qualitatively other. Some of this follows easily recognizable patterns and depends on easily understandable processes relating to the spatial and bodily limits of interaction. As Ash Amin expresses it, "Clearly, how people behave in a noisy square in which pedestrians are constantly avoiding other bodies and objects will be very different from that in a smaller square laid out for café life and convivial mingling" (Amin, 2008, p. 9). Amin goes on to further note how, conversely, spaces with similar patterns tend to share common social traits - in both vibrant and empty spaces, rhythms cause resonances between people and between people and environment, whereby "These resonances of situated multiplicity condition social action in quite powerful ways" (Amin, 2008, p. 13).

In more sparsely populated environments, there are spatial, logical, and social reasons for a stronger awareness of one another and such environments can make deeper forms of interaction easier (Giddens, 1984). Conversely, the impossibility of meeting everyone's gaze in the bustling street allows eye-contact to be avoided and people to act as if others were objects. While the anonymity of the crowd can offer a sense of freedom from control (De Beauvoir, 1965), the correspondence between physical co-presence and co-awareness is complex and often decreases with increasing masses. Arguably, there are thresholds where differences between the more and less intense spaces grow stronger, such as when the spatiality and materiality of one's own and others' bodies make itself present in more direct and intrusive ways (Grosz, 1995). Such situations induce a constant need to zig-zag, wait, pause, circumvent, or shift sideways in order to get through or to let others pass, or to avoid directly bumping into or being bumped into by others. The necessity of acknowledging corporeality and bodily mass transforms others' bodies, making them tend towards larger, continuous masses-and clearly, while perhaps not leading to the recognition of one another as individuals, there is interaction going on as well as negotiations and enactments of norms of behavior.

Calmer situations do not, of course, necessarily lead to conversations between strangers. However, they do tend towards increased attention being paid to individual actions and characters, suggesting that such spaces may aid in developing a more concrete understanding of just what others are doing in the same space. In moments of rest, we may develop a somewhat better understanding of who others are, and why they are where they are, than that which is to be gleaned in a fleeting encounter on the sidewalk of a bustling street. More time is likely to be spent seeing or hearing one another in calmer spaces, and conversations-or music playing from headphones- 
are more likely to be overheard. Low degrees of intensity may also witness stronger territorial effects (Brighenti \& Kärrholm, 2018), as specific choices about ways of inhabiting a calm space lead to palpable socioterritorial negotiations regarding subsequent acts of (co-)inhabitation.

Complex effects of "co-awareness" are also at play in such exchanges. A mutual gaze demands that the other be recognized as a subject (Calefato, 2004), and in this it also demands the recognition of one's own subjectivity - "who are you, and who am I (to you)?" (Butler, 2005). The precise situations of co-presence that can lead to such exchanges are of course intersectional: they are culturally and historically dependent and can be heavily affected by class stratification and gendered differentiation (Vincent, Neal, \& Iqbal, 2018). They are also not "inherently" positive since the questions raised in co-recognition or the situated sense of co-awareness can be highly exclusionary. If eye contact can trigger questions around belonging or the right to be somewhere, the answer may be a feeling that one should leave, generated even in the "fractions of a second ... before conscious reflections set in" (Swanton, 2010). Even the smallest of interactions can thereby develop into exclusionary practices and rhythms (Reid-Musson, 2018). While these kinds of exclusion are not intrinsically linked to whether one is a local inhabitant or not, their effects increase in line with expanded possibilities of continuous territorial domination.

Secluded spaces are, however, also indirectly interactive: in as far as that they are places of pause and rest, they are also places of avoidance (Koch, 2016). Their character is partially defined by not being a vibrant street or square - they are relationally "other," the place of fewer encounters than their counterpart. This recalls Zukin's and Kosta's account of the "off-Broadway" location, which is always dependent on Broadway and offers potentials for cultural differentiation with various "off-foreground" locations adopting different characteristics. Of the places addressed in this paper, perhaps Brända Tomten most clearly tends towards Zukin and Kosta's discussion of an "off-broadway" identity: a place "for those who know" (Zukin \& Kosta, 2004).

This emergent territoriality, which is negotiated in multifaceted ways, provides a further key to understanding how such sites work. Each site balances between personal, local, and global territoriality in its own particular way: if pulled further away from the foreground network, or further away from the decidedly shared public spaces of the city, such places may become local territory and thus subject to the effects of control and the limitations that such control brings (for better or worse). Similarly, if further integrated into the foreground, such places would not allow either local or temporal territoriality to claim them in ways that are necessary for some of the practices that today form their quality (see, e.g., Minoura, 2016). As spaces for "alterity," they can offer oases of possible temporary territorializations, emplacing "transpatial" community formations (Hillier \& Hanson, 1984) in "the heart" of dense settlements. They are places of otherness, alterity, and difference in complex and nuanced ways that include but are not limited to their slower rhythms. By being less continuously dominated by bodies and their territorial claims, or by certain groups of people or activities (neither locally controlled nor globally dominated), they are one important form of "the more intimate spaces of the city in which diverse individuals contest and negotiate their position in society and urban civic culture" (Hewitt, 2016, p. 358). Here, closeness to the intense public spaces is crucial-it affects the territorial negotiations of the site. Secluded spaces are not visited enough to become cosmopolitan spaces, yet not quite segregated enough to form full-on local territories. This is a complexity that offers pockets for visitors from all over the city to meet in relative seclusion, for visitors and locals to encounter one another in a different atmosphere, yet still for locals to claim space. The possibility of otherness and difference is central for social resilience, just as it is important for a diverse and inclusive democratic society (Williams, 2011). 


\section{Interface, Capacity, Insulation, and Sequencing}

While it is tempting to continue going deeper into the sociospatial situatedness of occupation, I will move on to the equally important matter of how these urban "pockets" or "fissures" (De Holanda, 2017) appear in the urban fabric as spatial configurations. What are the spatial conditions that such spaces share, which enable their existence as urban oases rather than as "vibrant, lively public spaces," "locally community spaces," or "distant' or 'peripheral' spaces of calm and respite.

The spaces explored in the observations all share a combination of closeness -in meters and configurative distance-and what Julienne Hanson has termed "insulation" (Hanson, 1998). For Hanson, insulation stands for the number of spaces in-between different rooms-for instance, between bedrooms and bathrooms or different bedrooms. Any space in-between "insulates" one space from another. The urban sites addressed earlier are invariably not directly adjacent to the most vibrant spaces: there is a minimum of one space in-between and they cannot be seen from the central arteries. This suggests that in urban fabrics, configurative insulation can be highly efficient-as Lars Marcus notes regarding another site on Södermallm, "Thus, a dramatic drop in integration is accomplished within an otherwise highly integrated area. This gives Bjursholmsplan a very special character, in that it is a rather segregated area, found just one or two steps from some of the most integrating lines of all on Södermalm" (Marcus, 2000, p. 126). However, while such spaces don't seem to need particularly much insulation, they are also dependent on not having too much as this would push them towards becoming "local" or "peripheral."

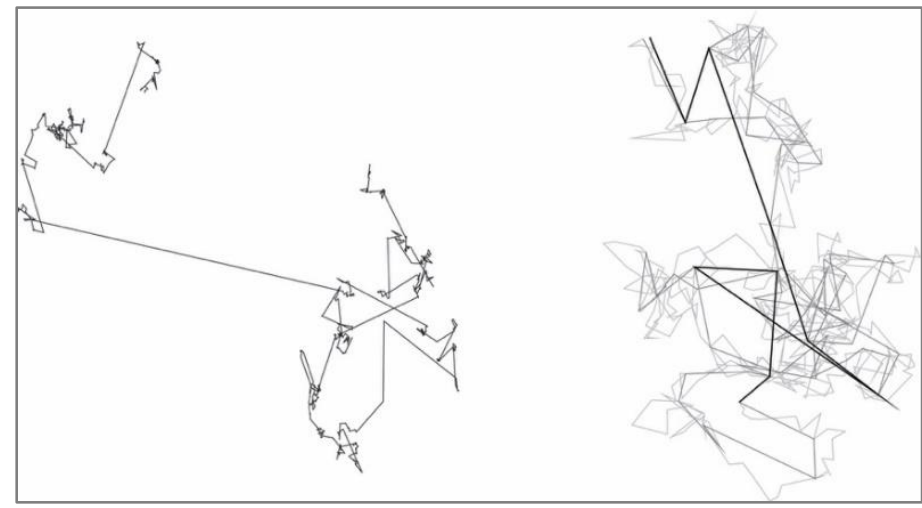

Figure 8 Lévy flight (left) and Brownian walk (right) search patterns; the Lévy flight is based on a mix of longer jumps between local searches, whereas the Brownian walk tend towards a more consistent distance. The figure of Brownian walk shows patterns from three different step lengths. Hillier's argument is that the foreground network in part operates by enabling 'local' searches in distant placessimilar to how Lévy flight search patterns work-rather than forming a network of origins and destinations 'of its own'. Figures adapted from Wikimedia Commons, Public domain license.

The second characteristic that these urban oases share can be understood through recourse to another of Hanson's terms, "sequencing," which describes the way in which spaces are configured one after the another (Hanson, 1998). Linked to the way Sophia Psarra discusses narrative (Psarra, 2009), sequencing also invokes the structural narrative and textural character that results from always already being embedded in networks through proximity to other spaces and by means of the way in which most trips to such a space (at least for non-locals) entail making use of the foreground network. Foreground and background networks, according to Hillier, can in turn be understood in terms of "Brownian" and "Levy-flight" search strategies (Figure 8) (Hillier, 2016, pp. 208-209), wherein the latter demonstrates how the foreground network can facilitate long-distance movement, while origins, destinations, or continued activity may disperse more widely in local contexts. Such an understanding thereby challenges the habit of making overly direct links between the question of "who" moves on particular segments and the configurational value of that segment, while refining our understanding of how the systemic role of a given space relates to how and why people are likely to use the foreground network when navigating longer distances. In this view, Västerlånggatan act as a "corridor" for most movements to or through the area of Gamla Stan in Stockholm, whether their destinations are on it or not, but does not define where people are 
headed. In this sense, arguably, the potentials of co-presence and experiencing difference that are engendered by vibrant places become at least partially integrated in the kind of places discussed here, as is the production of shared understandings of urbanity. However, the locations addressed in this paper are also sequenced on routes between other places; not being an "endpoint" seems to be important for upholding a potential blend of users as well as for being discovered by people. Such spaces are, as Alexander Ståhle expresses it, "in the way" (Ståhle, 2008). Departing from a simple reading of Ståhle's argument, it is important to understand that they are not, however, in "everyone's" way, and not for a (functionally) maximized number of visitors.

The third aspect the urban oases share is that they are part of what can be termed a "capacity system." For Lars Marcus, spatial capacity is the capacity of spatial configuration to carry difference, where this capacity is largely created by delimitations-for instance, two rooms can hold two different activities more easily than one room, etc. While this is usually translated to rooms in a building or, as in Marcus' own research, into plot subdivisions, I argue that the character of the squares and parks that I have observed largely comes from their multiplicity. While they hold some capacity internally - even if Brända Tomten has seen its capacity reduced by rearrangement of the outdoor serving-they form parts of a wider capacity together with other public spaces nearby. They are also relatively insulated relative to intensely used public squares (Bysistorget, Mariatorget, Järntorget, Stortorget, Nytorget, Björns Trädgård, and so on), and, for the parks, they are within walking distance to other, larger parks (Tantolunden, Högalidsparken, and Vitabergsparken). In this in-between, sets of squares and parks occupy a spectrum of positions creating bundles of off-site locations complementing the "vibrant" and the "peripheral." For most of them, one can find more stable or dynamic use of this in-between location for various activities, functions, or identities that deviate from main street culture. While one should be careful not to assume it is a perfect ecosystem, it is indeed an ecosystem where social (and functional) resilience in part comes from complementarity and degrees of interchangeability.

The fourth important shared factor lies in how the spatial interface of these observed spaces is structured to balance character and identity, occupying a space between decidedly local and visitordominated, which refines their capacity to contribute to the potential of offering different qualities of encounters and interactions between differences, and their potential to hold "alternate" atmospheres, activities and gatherings. An important factor here is the "integration interface," a measure of how the centrality of different scales overlaps, which provides statistical probabilities of people acting on different scales encountering one another, where the locally central streets of the discussed sites also have global importance (Hillier \& Hanson, 1984; Legeby, 2013; Peponis, Ross, \& Rashid, 1997). However, for these squares, I consider that closeness (which I define in a more colloquial sense as proximity between locations that offer a different social character) is as important, as well as how the interface between the different locations is structured in a concrete, architectural sense (Peponis et al., 2015). The sites are not strictly "segregated," but they are outside of the foreground network. They are locations that, as Peponis, Park, and Feng argue in relation to the spatial configuration of Gangnam in Seoul, Korea, "...allows the creation of local areas with distinct character, while enabling large scale metropolitan connectivity, by public transportation or privately used vehicles. It creates a variety of urban conditions in close proximity, thus setting the stage for a mixture of land uses or development densities and a pluralism of urban actors" (Peponis, Park, \& Feng, 2016, p. 105). While Peponis et al. discuss a larger and more dense metropolitan area than my Stockholm examples, and whilst they target other kinds of diversity than I interrogate here, the argument is relevant. In the places studied in my fieldwork, there is a finely grained balance and differentiation, whereby not only how locally dominated they are varies, but also who seems to be visiting them, and from where. Amongst the examples that I present, the ostensibly most homogenous population and most "local" character is to be found in St. Axel Landquist's Park, which is also furthest away from subway stations and closest to the "vibrant" space of Folkungagatan, which in turn (at this point) is also the weakest global connector. 


\section{Discussion and Conclusions: Resiliences of Capacity and Difference}

The kind of places studied here offer resilience in two important ways. These are both integrated and unrelated. First, these places are able to host changes in the use of urban space; second, these species have a capacity to carry difference in public space. ${ }^{1}$

The first aspect-capacity to host change-was clearly tested in the Covid-19 pandemic, wherein the extent to which urban textures were able to respond to restrictions and limitations depended on the closeness, plurality, and redundancy of open space (Legeby \& Koch, 2020). In the pandemic, this capacity was seen in places where there was more space than can be "efficiently used" in daily life, where space was distributed so that it was close-by, and where that space was diverse in the sense that it catered for different needs in the new situation. Without reducing the importance of larger recreational areas (Samuelsson et al., 2021), it is thus important to understand the ways in which public spaces are distributed and integrated in an urban texture that allow such diversity. But this capacity is fundamentally based on such spaces not being constantly full of activity in the regular, daily urban life-the standard evaluation of the "attractiveness" or "success" of a placesince that would leave them little to no capacity to host the new activities emerging. This, furthermore, quite clearly demonstrates what holds true also without a pandemic: if all public space is vibrant and full of activity, there are few openings for acting otherwise.

"Off-foreground" can here be seen as a term for "accessible but calm." To return to the work of Engström and Gren that is brought up in the introduction to this paper, the kind of places studied here seem to be able to capture two out of the three things that people value most in a park: what the authors, following Grahn and Stigsdotter (2003), call the "serene" and "space," whereas "nature," the third category, is more dependent on size. However, the findings here suggest that while they make an important point, these scholars may have overestimated the importance of size: while size is one way through which one can achieve "enough space to not frequently encounter other people, or to avoid experiencing disturbance from traffic etc." (Engström \& Gren, 2017, p. 21), a more nuanced and detailed study of how architectural articulations shape the use and experience of public space would offer further means by which to create such conditions (see Okba, Cutini, Leccese, Salvadori, \& Zemmouri, 2021).

These spaces explored in this paper offer further potentials for delivering resilience, both indirectly (as calm, secluded, and quiet space), and through their "un-use." While the most intensely used spaces may need to adapt to primarily human conditions and intense wear-and-tear, these sites demonstrate further, largely untapped, potential for including "the other," and for "wildlife" and species of plants and animals that don't play nicely with the bustling high-street. This suggests possibilities for ecological networks to be established in parallel to human systems, operating not at and through the main human arteries but covering similar ground, without excluding humans or forming peripheries.

This is not to suggest that these spaces are ideal. Their capacity to hold alterity should not be over-romanticized either in how far it reaches, in how allowing they are, or in that such alterity is always only positive. If the most vibrant spaces prevent certain things happening, so do the characters of these spaces, including positive aspects of the former. In the current state of the given examples, some of the capacities and potentials discussed are rather prevented than supportedby car-parking, outdoor dining areas, or other acts. My intent has not been to romanticize these places, but rather to address their potential as spaces of rest that are remarkably close to intense,

\footnotetext{
${ }^{1}$ While I have not investigated how disruptions would affect the configurative system or change accessibilities to amenities (Abshirini \& Koch, 2017; Carpenter, 2015; Cutini, Farese, \& Rabino, 2020; Koch \& Miranda, 2013), arguably there is a link between the preliminarily observed demands for multiplicity and resilience against disruptions in a spatial system. Such multiplicity would, furthermore, be in line with the first principle of "building resilience" as presented by Karen Kotschy et al: "Maintain diversity and redundancy" (Kotschy, Biggs, Daw, Folke, \& West, 2015). Neither have I directly addressed resilience in relation to urban ecosystems or ecosystem services (Barthel \& Kyttä, 2020; Biggs, Schlüter, \& Schoon, 2015; Erixon Aalto, Marcus, \& Torsvall, 2018; Marcus, Berghauser Pont, \& Barthel, 2019).
} 
vibrant urban spaces - and to open up for more careful consideration of how to handle such spaces, respecting and working with this quality, including their non-use.

That it is relatively easy to create spaces of low use in dense urban fabrics does not mean that it is easy to make such spaces qualitative, nor that they by necessity support deeper or more intense interactions. If the intent is to work with these kinds of places and offer a triad of resilience values in the form of a "pause" from urban vibrancy, openings for alternate activities and identities, and a capacity to host change of use of public space in extraordinary conditions, further questions remain with respect to these demands. In addition, while their social character may offer possibilities for other relations between humans and non-humans to be construed than in the most populated, intensely used public spaces, this presents a largely untapped resource.

\section{Acknowledgements}

This paper stems in part from discussions with Åsa Green at the Stockholm Resilience Centre regarding if and how quiet spaces of rest can be created inside urban environments. It is also heavily indebted to long-term discussions with John Peponis at GeorgiaTech regarding the concept of interface, more so than is shown in the references, as our exchange has concerned ongoing and forthcoming work.

\section{References}

Abshirini, E., \& Koch, D. (2017). Resilience, space syntax and spatial interfaces: The case of river cities. A/Z ITU Journal of the Faculty of Architecture, 14(1), 25-41.

Amin, A. (2008). Collective culture and urban public space. City, 12(1), 5-24.

Anderson, J., Ruggeri, K., Steemers, K., \& Huppert, F. (2016). Lively Social Space, Well-Being Activity, and Urban Design: Findings From a Low-Cost Community-Led Public Space Intervention. Environment and Behavior, 49(6), 685-716.

Barthel, S., \& Kyttä, M. (Eds.). (2020). Urbanization and Affordances that Promote Well-Being for (Urban) People and for a Healthy Biosphere: Frontiers Media.

Biggs, R., Schlüter, M., \& Schoon, M. L. (Eds.). (2015). Principles for Building Resilience: Sustaining Ecosystems Services in Social-Ecological Systems. Cambridge: Cambridge University Press.

Bohman, H., Ryan, J., Stjernborg, V., \& Nilsson, D. (2021). A study of changes in everyday mobility during the Covid-19 during the Covid-19 pandemic: As perceived by people living in Malmö, Sweden. Transport Policy, 106, 109-119.

Brighenti, A. M., \& Kärrholm, M. (2018). Beyond Rhythmanalysis: towards a territoriology of rhythms and melodies in everyday spatial activities. City, Territory and Architecture, 5(4).

Brighenti, A. M., \& Kärrholm, M. (2020). Animated lands: studies in territoriology. Lincoln: University of Nebraska Press.

Butler, J. (2005). Giving an Account of Oneself. New York: Fordham University Press.

Calefato, P. (2004). The Clothed Body (L. Adams, Trans.). Oxford: Berg.

Carpenter, A. (2015). Resilience in the social and physical realms: Lessons from the Gulf Coast. International Journal of Disaster Risk Reduction, 14(3), 290-301.

Choi, E. (2014). Walkability and the complexity of walking behavior. A/Z ITU Journal of the Faculty of Architecture, 11(2), 87-99.

Choi, E., \& Koch, D. (2015). Movement and the connectivity of streets: A closer look at route distribution and pedestrian density. In K. Karimi, L. Vaughan, K. Sailer, G. Palaiologou, \& T. Bolton (Eds.), Proceedings of the 10th International Space Syntax Symposium (pp. 65:61-65:11). London: UCL.

Cutini, V., Farese, D., \& Rabino, G. (2020). Configuration and resilience: some remarks from the cases of Florence and Milan. Plurimondi, 18, 35-51.

de Beauvoir, S. (1965). The Prime of Life (P. Green, Trans.). Harmondsworth: Penguin.

de Holanda, F. (2017). Urban Fissures. Journal of Space Syntax, 7(2), 141-164.

de la Fuente, P. P. (2015). Discrete Architectures: Rhythms of public eating in Värnhemstorget in Malmö. In M. Kärrholm (Ed.), Urban Squares: Spatio-temporal studies of design and everyday life in the Öresund region (pp. 57-86). Lund: Nordic Academic Press.

Engström, G., \& Gren, Å. (2017). Capturing the value of green space in urban parks in a sustainable urban planning and design context: pros and cons of hedonic pricing. Ecology and Society, 22(2), 21.

Erixon Aalto, H., Marcus, L., \& Torsvall, J. (2018). Towards a Social-Ecological Urbanism: Co-Producing Knowledge through Design in the Albano Resilient Campus Project in Stockholm. Sustainability, 10(3), 717. 
Giddens, A. (1984). The Constitution of Society: Outline of the Theory of Structuration. Berkeley: University of California Press.

Grahn, P., \& Stigsdotter, U. A. (2003). Landscape planning and stress. Urban Forestry \& Urban Greening, 2(1), 1-18.

Grosz, E. (1995). Space, time, and perversion: Essays on the politics of bodies. London: Routledge.

Hanson, J. (1998). Decoding homes and houses. Cambridge, UK: Cambridge University Press.

Hewitt, T. (2016). Rethinking Encounter: intercultural interactions between parents in Australia's culturally diverse primary schools. Australian Geographer, 47(3), 355-370.

Hillier, B. (1999). Centrality as a process: acounting for attraction inequalities in deformed grids. Urban Design International, 4(3-4), 107-127.

Hillier, B. (2009). Spatial Sustainability in Cities: Organic Patterns and Sustainable Forms. In D. Koch, L. Marcus, \& J. Steen (Eds.), Proceedings of the 7th International Space Syntax Symposium (pp. K01:01-20). Stockholm: KTH.

Hillier, B. (2016). What are cities for? And how does this relate to their spatial form? Journal of Space Syntax, 6(2), 199-212.

Hillier, B., \& Hanson, J. (1984). The Social Logic of Space. Cambridge, UK: Cambridge University Press.

Irschik, E., \& Kail, E. (2013). Vienna: Progress Towards a Fair Shared City. In I. S. de Madariaga \& M. Roberts (Eds.), Fair Shared Cities: The Impact of Gender Planning in Europe (pp. 193-230). London: Routledge.

Kärrholm, M. (2012). Retailising Space: Architecture, Retail and the Territorialisation of Public Space. Burlington: Ashgate.

Koch, D. (2016). On Avoidance: Reflections on Processes of Socio-spatial Structuring. Civil Engineering and Architecture, 4(2), 67-78.

Koch, D. (2017). Memory, Projection, and Imagination: On Challenges for Observation and Statistics Based Research. Contour 2: Agents/Agency of Urbanity, 2(1), 1-15.

Koch, D. (2021). The Bubble, the Arrow, and the Area: Urban Design and Diagrammatic Concepts of Human Action. In L. Medrano, L. Recaman, \& T. Avermaete (Eds.), The New Urban Condition: Criticism and Theory from Architecture and Urbanism (pp. 183-208). London: Routledge.

Koch, D., \& Miranda, P. (2013). Syntactic Resilience. In Y. O. Kim, H. T. Park, \& K. W. Seo (Eds.), Proceedings of the Ninth International Space Syntax Symposium (pp. 054:051-054:016). Seoul: Sejong University.

Koch, D., \& Sand, M. (2009). Rhythmanalysis - Rhythm as Mode, Methods and Theory for Analysing Urban Complexity. In A. Wesener \& M. Aboutarabi (Eds.), Urban Design Research: Method and Application Proceedings of the International Conference held at Birmingham City University 3-4 December 2009 (pp. 61-72). Birmingham: Birmingham City University.

Kotschy, K., Biggs, R., Daw, T., Folke, C., \& West, P. (2015). Princple 1 - Maintain diversity and redundancy. In R. Biggs, M. Schlüter, \& M. L. Schoon (Eds.), Principles for Building Resilience: Sustaining Ecosystem Services in Social-Ecological Systems (pp. 50-79). Cambridge: Cambridge University Press.

Lefebvre, H. (1991). The production of space (D. Nicholson-Smith, Trans.). Oxford: Blackwell Publishing.

Lefebvre, H. (1996a). Seen from the Window (E. Kofman \& E. Lebas, Trans.). In E. Kofman \& E. Lebas (Eds.), Writings on Cities (pp. 219-227). London: Blackwell.

Lefebvre, H. (1996b). Writings on Cities (E. Lebas \& E. Kofman, Trans.). Oxford: Blackwell.

Lefebvre, H. (2004). Rhythmanalysis: Space, time and everyday life (S. Elden \& G. Moore, Trans.). London: Continuum.

Lefebvre, H., \& Régulier, C. (2004). Attempt at the Rhythmanalysis of Mediterranean Cities (S. Elden \& G. Moore, Trans.). In H. Lefebvre (Ed.), Rhythmanalysis: Space, time and everyday life (pp. 87-100). London: Continuum.

Legeby, A. (2013). Patterns of Co-Presence: Spatial Configuration and Social Segregation. Stockholm: KTH.

Legeby, A., \& Koch, D. (2020). The changing of urban habits during the Corona pandemic in Sweden. FAMagazine, 52-53, 198-203.

Ludvigsson, J. F. (2020). The first eight months of Sweden's COVID-19 strategy and the key actions and actors that were involved. Acta Paediatrica, 109(12), 2459-2471.

Marcus, L. (2000). Architectural knowledge and urban form: The functional performance of architectural urbanity. Stockholm: KTH.

Marcus, L., Berghauser Pont, M., \& Barthel, S. (2019). Towards a socio-ecological spatial morphology: integrating elements of urban morphology and landscape ecology. Urban Morphology, 23(2), 115-124.

Minoura, E. (2016). Uncommon Ground: Urban Form and Social Territory. Stockholm: KTH.

Netto, V. (2008). Practice, space, and the duality of meaning. Environment and Planning D: Society and Space, 26(2), 359-379. 
Okba, B., Cutini, V., Leccese, F., Salvadori, G., \& Zemmouri, N. (2021). Relation between soundscape and spatial configuration in different urban contexts. INTER-NOISE and NOISE-CON Congress and Conference Proceedings, 263(5), 1405-1414.

Osman, R., \& Mulíček, O. (2017). Urban chronopolis: Ensemble of rhythmized dislocated places. Geoforum, 85, 46-57.

Park, G., \& Evans, G. W. (2016). Environmental stressors, urban design and planning: implications for human behaviour and health. Journal of Urban Design, 21(4), 453-470.

Peponis, J. (2017). On the pedagogical functions of the city: a morphology of adolescence in Athens, 1967 1973. Journal of Space Syntax, 7(2), 219-251.

Peponis, J., Feng, C., Green, D., Haynie, D., Kim, S. H., Sheng, Q., Wang, H. (2015). Syntax and parametric analysis of superblock patterns. Journal of Space Syntax, 6(1), 109-141.

Peponis, J., Park, J., \& Feng, C. (2016). The city as an interface of scales: Gangnam urbanism. In S. H. Kim, E. Cinn, K. Ahn, S. Kim, I. Chung, D. E. Jeong, \& R. Enos (Eds.), The FAR Game: Constraints Sparking Creativity (pp. 102-111). Seoul: SPACE books.

Peponis, J., Ross, C., \& Rashid, M. (1997). The Structure of Urban Space, Movement and Co-presence: The Case of Atlanta. Geoforum, 3-4, 341-358.

Psarra, S. (2009). Architecture and narrative: The formation of space and cultural meaning. London: Routledge.

Reid-Musson, E. (2018). Intersectional rhythmanalysis: Power, rhythm, and everyday life. Progress in Human Geography, 42(6), 881-897.

Revol, C. (2019). Rue Rambuteau Today: Rhythmanalysis in Practice. Rhuthmos. Retrieved from https://rhuthmos.eu/spip.php?article549

Roe, J., \& McCay, L. (2021). Restorative Cities: Urban design for mental health and wellbeing. London: Bloomsbury.

Samuelsson, K. (2021). Making space for resilient urban well-being. Gävle: Gävle University Press.

Samuelsson, K., Barthel, S., Giusti, M., \& Hartig, T. (2021). Visiting nearby natural settings supported wellbeing during Sweden's “soft-touch" pandemic restrictions. Landscape and Urban Planning, 214, 104176.

Sand, M. (2011). Gå vilse med punktlighet och precision: en guidebok A-Ö. Stockholm: ArkDes.

Ståhle, A. (2008). Compact sprawl: Exploring public open space and contradictions in urban density. Stockholm: KTH.

Stavroulaki, G., Bolin, D., Berghauser Pont, M., Marcus, L., \& Håkansson, E. (2019). Statistical modelling and analysis of big data on pedestrian movement. In Proceedings of the 12th International Space Syntax Symposium (pp. 79.71-79.24). Beijing: Beijing Jiaotong University.

Swanton, D. (2010). Flesh, metal, road: tracing the machinic geographies of race. Environment and Planning D: Society and Space, 28, 447-466.

United Nations. (2015). Transforming our World: The 2030 Agenda for Sustainable Development. United Nations

Verschaffel, B. (2010). Guessing the Future of the Library. In H. H. van der Werf (Ed.), The Architecture of Knowledge: The library of the future (pp. 84-95). Rotterdam: NAi.

Vincent, C., Neal, S., \& Iqbal, H. (2018). Friendship and Diversity: Class, Ethnicity and Social Relationships in the City. Cham: Palgrave Macmillan.

Walker, B., Holling, C. S., Carpenter, S. R., \& Kinzig, A. (2004). Resilience, Adaptability and Transformability in Social-ecological Systems. Ecology and Society, 9(2), 5.

Williams, J. P. (2011). Subcultural Theory: Traditions and Concepts. Cambridge: Polity Press.

Zukin, S. (1995). The Cultures of Cities. Oxford: Blackwell.

Zukin, S., \& Kosta, E. (2004). Bourdieu Off-Broadway: Managing Distinctionon a Shopping Block in the East Village. City \& Community, 3(2), 101-114.

\section{Resume}

Daniel Koch is a docent in Architecture and researcher in urban design and urban theory at the KTH School of Architecture, where he leads the development of the profile critical morphology and spatial analysis. He is also co-programme director of the master's programme in Sustainable Urban Planning and Design. His research investigates spatial configuration, diagrams and abstractions, and processes of subjectification within the larger frame of architectural theory and design, as well as urban sustainability and diversity. 